\title{
Veronika Niederhofer
}

\section{Konversion in den Paulus- und Theklaakten}

\author{
Eine narrative Form der Paulusrezeption
}

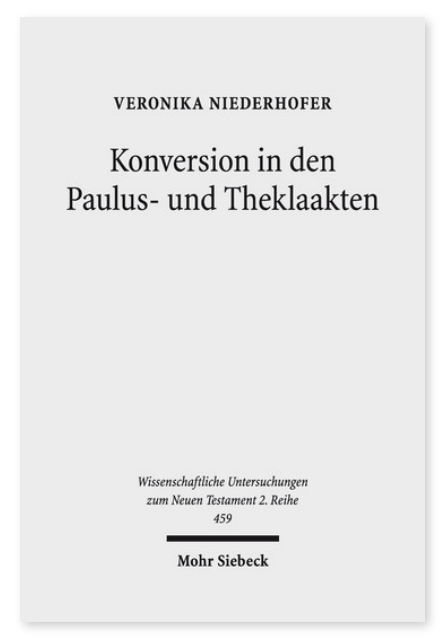

2017. XII, 279 Seiten. WUNT II 459

ISBN 978-3-16-155829-0

DOI 10.1628/978-3-16-155829-0

eBook PDF 109,00€

ISBN 978-3-16-155143-7

fadengeheftete Broschur 109,00€
Die Paulus- und Theklaakten erzählen, wie Thekla zur Christin und Verkünderin des christlichen Glaubens wird. Welche frühchristlichen Vorstellungen über Konversion, Nachfolge und Glaubensentwicklung lassen sich dieser Erzählung entnehmen? Und welche Informationen über das sukzessive Eindringen des Christentums in die antike Gesellschaft im ausgehenden zweiten Jahrhundert bietet der Text?

Mit der Analysemethode der narrativen Exegese gelingt es Veronika Niederhofer, die Paulus- und Theklaakten als historisch und theologisch bedeutungsvolle Quellen für die frühchristliche Frömmigkeit und deren Vorstellungswelt einzuordnen: Die Autorin zeigt, dass die Erzählung als Mehr-Ebenen-Drama gelesen werden kann, das die Thematik Konversion paradigmatisch als einen dynamischen und mehrstufigen Prozess, als einen Weltenwechsel beschreibt. Dabei zeigt sich, dass der Verfasser durch narrative Umsetzung kanonischer Texte, insbesondere paulinischer Gedanken, auf subtile und neue Art Paulusexegese betreibt.

Veronika Niederhofer Geboren 1986; Studium der Theologie in Regensburg und Leuven; Wiss. Assistentin am Lehrstuhl für Exegese und Hermeneutik des Neuen Testaments in Regensburg; 2016 Promotion; seit 2017 Bildungsreferentin beim Forum für Hochschule und Kirche e.V. der DBK in Bonn.

Jetzt bestellen:

https://mohrsiebeck.com/buch/konversion-in-den-paulus-und-theklaakten-9783161558290?no_cache=1 order@mohrsiebeck.com

Telefon: +49 (0)7071-923-17

Telefax: $+49(0) 7071-51104$ 